\title{
ERRATUM TO: CALL FOR PAPERS
}

\section{Erratum to: Int $J$ of Sci and Math Educ}

DOI 10.1007/s10763-012-9394-4

The deadline for our ongoing special issue "Neuroscience Perspectives for Science and Mathematics Learning in Technology-Enhanced Learning Environments" was extended from from May 1, 2013 to July 15, 2013.

National Taiwan University of Science and Technology

Taipei, Taiwan

E-mail: mjtsai99@mail.ntust.edu.tw

The online version of the original article can be found under doi:10.1007/s10763-012-9394-4. 